\title{
Sistemas familiares conflituosos e cuidado feminino com crianças acolhidas
}

\author{
Sistemas familiares conflictivos y cuidado femenino con niños acogidos
}

Conflicting family systems and female care with institutionalized children

\author{
Lucas Fadul de Aguiar \\ Edson Júnior Silva da Cruz \\ Janari da Silva Pedroso
}

Universidade Federal do Pará (UFPA), Belém, PA, Brasil

\begin{abstract}
Resumo
O estudo de famílias como um sistema permite desfocalizar sofrimentos e problemáticas em uma única pessoa. Essa compreensão facilita entender o cuidado realizado por mulheres com seus filhos, a partir das heranças transgeracionais que compõe a história de vida familiar. Em casos extremos no cuidado, a criança pode parar em uma instituição de acolhimento infantil.A presente pesquisa investigou a relação entre crianças institucionalizadas e a dinâmica de suas famílias num serviço de acolhimento para crianças de zero a seis anos. Trata-se de um estudo de caso com duas famílias e com os seguintes instrumentos: entrevistas semiestruturadas e o genograma. A discussão dos resultados evidenciou que a herança de abandono foi atualizada em até três gerações, a partir de uma história que se construiu a base de perdas emocionais e financeiras. Tais perdas foram somadas as dificuldades do núcleo, ao exteriorizarem conflitos que resultaram na posterior desagregação familiar e acolhimento infantil.
\end{abstract}

Palavras-chave: Dinâmica Familiar; Cuidado Feminino; Transmissão Transgeracional; Genograma; Crianças Institucionalizadas.

\begin{abstract}
The understanding of families like systems allows defocus problems and sufferings on one single person. When this logic is used do compreheend female care, it is perceptive that the way women deal with their children is influenced bytransgenarational heritage whose shape the story of the group - which may be enriched or dreadful. In extreme cases, the child goes to a shelther care. This research aimed investigate how family system dynamic contributed to the stay of one of their children in a institutionalized space. The multiple case study was used as the method, whereby semi-estructured interview and genogram were the following instruments. As results' discussion, it was evidenced the abandonment's inheritance refreshed in three generations, based on a story of financial and emotional losses. These losses were added to the difficulties of the nucleus, when externalizing conflicts that resulted in the subsequent family disaggregation and child care.
\end{abstract}


Keyword: Dynamic Family; Female Care; Transgenerational Transmission; Genogram; Institutionalized Children

\section{Resumen}

El estudio de familias como un sistema, permite desfocalizar sufrimientos y problemáticas en una única persona. Esta visión, facilita entender el cuidado realizado por mujeres con sus hijos, el cual es influenciado por las herencias transgeneracionales que componen la historia de vida -las cuales pueden ser enriquecedoras o conflictivas. En casos extremos en el cuidado, el niño puede ir a parar a una institución de acogida infantil. La presente investigación indagó la relación entre niños institucionalizados y la dinámica de sus familias. Se trata de un estudio de casos múltiples desarrollada con entrevistas semiestructuradas y genograma. La discusión de los resultados evidenció que la herencia del abandono influyó en hasta tres generaciones, a partir de una historia que se construyó en pérdidas emocionales y financieras. Tales pérdidas se sumaron a las dificultades del núcleo, al exteriorizar conflictos que resultaron en la posterior disgregación familiar y en la institucionalización infantil.

Palabras clave: Dinámica Familiar; Cuidado Femenino; Transmisión Transgeneracional; Genograma; Niños Institucionalizados.

\section{Introdução}

A mulher desempenha papel preponderante nas práticas de cuidado, em especial ao se tratar do cuidado para com seus filhos e filhas. Historicamente, as mulheres se viram na incumbência de tomar conta tanto da preservação física e moral de suas residências e da sua prole sendo a casa, a companheira e as crianças propriedades do homem. Esta forma de arranjo familiar tradicional é tida como nuclear, com a divisão rígida e específica de papéis sociais para homens e mulheres (Brito, 2008).

Contudo, com a presença feminina mais competitiva no mercado de trabalho a partir da metade do século XX, deu-se início um ciclo profundo de transformações que influenciaram as dinâmicas até então institucionalizadas, em que as atribuições familiares não mais se limitam à divisão por sexo ou geração. Porém, mesmo que se tenha flexibilizado e descontruído a divisão de papéis sociais entre homens e mulheres, ainda se observa o enraizamento dos mesmos no cotidiano. Algo que coloca à prova novas produções culturais e práticas de cuidado, imiscuídas de antigas responsabilidades, pautadas em construções de gênero tradicionais (Fukuda, Penso \& Santos, 2013).

Isto fica evidente no estudo de Pines-Gassman (2011) com 61 mães entrevistadas que relataram cuidar sozinhas de seus filhos, tendo que arcar com as 
responsabilidades maternas e conciliá-las com seu emprego, tarefas de casa e ainda encontrar tempo hábil para o cuidado pessoal e o lazer. Quando questionadas qual o papel de seus (ex)companheiros, relataram de forma objetiva que os mesmos se preocupavam majoritariamente em contribuir financeiramente com o sustento da residência e/ou custear a educação dos filhos.

Há de se ressaltar que o desdobramento do conceito de cuidado, a priori, segue uma definição simplista que leva em conta as principais necessidades que cada pessoa carrega ao longo do seu ciclo vital, tais como: alimentação, afeto e interação social. Por meio destes parâmetros, o cuidar - seja o de si, ou o de outros - vincula-se ao atendimento de um rol de características que parecem universais ao ser humano. No entanto, ao se pensar dessa forma, aspectos culturais presentes na estrutura social de cada comunidade permanecem negligenciados; afinal, cada população possui suas próprias concepções do que é saúde, doença e também de cuidado (Zanatta \& Motta, 2007).

Logo, as noções e práticas de cuidado se encontram relacionadas à cultura específica de um povo, em um dado território e momento histórico. Colocar em evidência tal perspectiva põe em discussão a necessidade de enxergar a própria complexidade do que significa cuidar; não apenas como compreensão de diferentes saberes, mas sim como maneira de desnaturalizar preconcepções sobre o cuidar que poderiam classifica-lo de forma moralizante ou avaliativa. Tal postura não leva em conta a dinamicidade de situações e contextos que podem resultar em formas de cuidar consideradas danosas ou negligentes dentro de um prisma, porém tidas como as respostas possíveis para um dado meio (Cardoso, 2011).

Dessa forma, torna-se premente validar as diferentes práticas de cuidado o que não implica deixar de lado a problematização necessária quanto as suas consequências, nem menos suas origens; assim, o aparente "não cuidar", o abandono, as práticas educativas punitivas são experiências culturais cuidadoras que também advém de regras, valores e possibilidades sociais, mesmo que implícitas ou não ditas. A reflexão a ser colocada, portanto, está para além de definir de forma fechada o sentido de cuidado, mas sim perceber como este se manifesta (Bucher-Maluschke, 2008).

\section{A Transgeracionalidade no Cuidado}

\section{Feminino}


Para compreender os padrões atuais de cuidado de forma ampla é preciso retomar o passado. Faz-se necessário ter acesso à herança cultural e histórica que demarcam os traços de vida de pessoas, comunidades e grupos sociais mais abrangentes; da unidade à coletividade, comportamentos, crenças e ideologias pleiteiam sua própria sobrevivência ao longo de gerações. A razão pela qual tal fenômeno ocorre se explica à medida em que o ser humano, enquanto unidade, busca sentido da sua própria existência; ao perde-la ou tê-la em bases abaladas, sua fragilidade fica exposta. Assim, é preciso criar mecanismos que permitam a perpetuação de valores que organizem a vida social dentro dos moldes que validem sua maneira de significar e lidar coma realidade (Carter \& McGoldrick, 1995).

A repetição de padrões, seja na forma de agir ou simbolizar o mundo, apenas acontece no que se conceituou como sistemas. Cada sistema envolve determinada produção cultural que se manifesta de forma consciente ou não em suas unidades (indivíduos) e em grupos. No entanto, os sistemas não são necessariamente fechados - possuem maior ou menor abertura, de acordo com as particularidades que os demarcam; caso fosse o contrário, não se veriam mudanças sociais e políticas ao longo da história.
Assim, o tradicional e o passado se movimentam junto às transformações presentes em formas de coexistência que variam desde à acomodação até o conflito (Rocha-Coutinho, 2006).

Pode-se apreender, diante desta conclusão, que os sistemas nos quais pessoas e grupos se inserem, não são todos unificados, harmoniosos, que vivem unicamente para perpetuarem sua própria cultura; pelo contrário, podem ser marcados por rupturas, entrechoques ou opressões silenciosos que delineiam a convivência entre pessoas. Isto fica evidente nas relações de gênero da atualidade, as quais são marcadas pela tensão de muitas mulheres que já não mais aceitam lugares tradicionalmente impostos - no estereótipo de mãe, que apenas cuida do lar, dos filhos e do marido (Diniz, 2011).

Desse modo, as convergências e contradições de um sistema são perpassadas em alguma medida às pessoas que o compõe. Para se compreender a forma como isto ocorre, torna-se patente pôr em análise o primeiro grupo responsável pela socialização dos indivíduos ao convívio social: a família. A partir dela são impostos hábitos e padrões de comportamento, por meio de trocas afetivas e de informações. Nesse ponto, coloca-se em consideração que tanto as 
unidades quanto os grupos não apenas representam sistemas. São a própria concretização destes (Krom, 2000).

Assim, os sistemas se perpetuam por meio das famílias, responsáveis por inserirem seus membros na cultura que as circunscreve. Esta preservação - seja do sistema, dos grupos ou dos indivíduos não acontece dentro de uma única geração; são padrões que se repetem e atualizam ao longo da história em diversas gerações, transmitida de forma transversal. Por esta razão, padrões de comportamento e crenças são entendidos em seu percurso transgeracional, enquanto um contínuo que enfrenta contingências que demarcam sua história (Almeida, Magalhães \& FéresCarneiro, 2014).

Entender, por meio dessa perspectiva, o cuidado feminino para com os seus filhos na atualidade é observar a transgeracionalidade familiar em que as mulheres estão sendo envolvidas, de forma a abarcarem repetições que enquadram hábitos e costumes já estabelecidos, assim como as rupturas que marcam as transformações nos papéis de gênero atuais. São histórias que perpassam pela relação com suas mães e avós, assim como membras femininas da sua própria geração; é, sobretudo, os diversos eventos que marcam suas vidas, que envolvem os componentes masculinos e os acontecimentos vinculados forçosamente à condição de ser mulher (Wendt dos Santos \&Moré, 2011).

A partir desse exposto, Cardoso (2011) pontua que o cuidado feminino no século XXI passa por transformações implicadas diretamente na própria forma como as famílias se organizam atualmente. O modelo tradicional e nuclear convive com diferentes conceitos de família, os quais variam desde os casais homoafetivos até a monoparentalidade e pessoas divorciados com guarda compartilhada. Dentre esses, sobressai o modelo no qual as mulheres convocam a presença de suas próprias mães - avós das crianças -, irmãs ou alguém da família estendida para assessorar na tarefa com os filhos.

Compreende-se, dessa forma, de um ponto de vista de múltiplas gerações, o gênero feminino emerge como papel de cuidado, mas também como principal transmissor direto dos padrões daquela família. A problemática que se abstrai dessa assertiva é feita a partir do momento que se pontua os conflitos daquele núcleo; em outras palavras, não apenas cabe as mulheres o cuidado - de forma consciente; é igualmente imposto a responsabilidade de acomodar a sobrecarga e dissabores que envolvem esse cuidar. Além disto, sobra a culpabilização quando este processo não 
ocorre de acordo com as demandas sociais (Knoester\&Carlson, 2011).

As principais implicações desse fatos e encontram na dificuldade das mulheres em encontrar equilíbrio para essas demandas sociais, por estabelecerem patamares excruciantes a ser atingidos; soma-se ainda a questão que cuidar dos filhos não se resume a apenas dedicar o tempo pessoal a eles, como também encontrar espaço para realizar atividades domésticas que influenciam nesse cuidado (Teixeira \&Villachan-Lyra, 2015).Desse modo, o excesso de responsabilidades não afeta apenas as cuidadoras, mas também suas crianças, obrigadas desde cedo a lidar também com dificuldades. É um ciclo que se retroalimenta: o cuidado feito exclusivamente pelas mulheres soma-se as dificuldades que permeiam as demais facetas do seu cotidiano. Não à toa, $42 \%$ do público infantil em instituições de acolhimento tem na figura feminina a única representante legal. Esse formato oferece o primeiro passo para que as futuras gerações de infantes herdem histórias sacrificantes, em que suas próprias necessidades por cuidado não são inteiramente satisfeitas (Fukuda, Penso \& Santos, 2013).

\section{Da Transgeracionalidadedo Cuidado} Feminino ao Acolhimento Infantil
As consequências de uma cultura que ainda procura manter a mulher contemporânea dentro de um papel social tradicional se refletem de forma prejudicial em todo o sistema, de forma transgeracional. Em um mundo globalizado, com a entrada definitiva da figura feminina no mercado de trabalho, as práticas de cuidado com crianças podem vir ao encontro de mudanças que flexibilizem a função dos genitores na criação dos filhos, ou atuarem na manutenção de antigos padrões (Brito, Cardoso \& Oliveira 2010).

A questão a ser colocada quando se trabalha com a variável criança está em outros fatores que permeiam esse cuidado, como: situação socioeconômica, a dinâmica familiar e as características pessoais dos cuidadores que podem levar os infantes a situações extremas de abandono e negligência familiar, a exemplo do acolhimento institucional. Silva, Magalhães e Cavalcante (2014) salientam a preocupação quando a dinâmica familiar passa a se organizar em torno desses fatores, de modo a se configurarem em padrões geracionais que se imiscuem nas próprias práticas de cuidado - sejam estas conscientes ou não.

A discussão do acolhimento institucional é posta em evidência ao se 
problematizar situação do cuidado feminino contemporâneo por este evento o de pôr a criança sob a supervisão de terceiros que não a família -, ao colocar de forma contundente como o funcionamento de determinados sistemas levam a caminhos desinteressantes para o desenvolvimento da sociedade como um todo: dos seres humanos que se tornarão parte produtiva do corpo social um dia, das mulheres que buscam novos modos de vida. A visão sistêmica e transgeracional possibilita desfocalizar a análise sectária de apenas um personagem em detrimento do outro, para colocá-las como um todo unificado (Bucher-Maluschke, 2008).

No cenário atual, há diversas casas de acolhimento institucional espalhadas pelo Brasil que recebem crianças e adolescentes. As condições que levam a esse acolhimento são a de direitos ameaçados ou violados, seja por ação ou omissão da sociedade, do Estado e/ou ainda pela conduta dos pais/responsáveis; quanto ao comportamento dos cuidadores, a negligência, o abandono, a violência, a ameaça e o abuso entrariam como categorias generalizantes. Ainda assim, o convívio familiar é tido como prioritário, sendo a medida de colocar as pessoas em condição infantil em instituições que acolham considerada provisória e excepcional (Lei $\left.\mathrm{n}^{\circ} 8.06,1990\right)$, entretanto, apesar do previsto no ECA, os estudos mostram que algumas práticas não são efetivamente realizadas como preconizadas no Estatuto (Cavalcante, Silva \& Magalhães, 2010, Iannelli, Assis \& Pinto, 2015).

Desse modo, mesmo que o acolhimento ocorra, o trabalho para reintegração familiar ocorre em paralelo; o estatuto inclusive prevê que a possibilidade de acolher uma criança deva ocorrer em última medida, após serem esgotadas todas as oportunidades de resolução do contexto que levou ao encaminhamento institucional. Tal assertiva é imposta de tal forma por se entender que a pessoa em desenvolvimento já se encontra inserida dentro de um núcleo e dinâmica familiar, dos quais minimamente já se vê vinculada.

Importante destacar que para ocorrer a preparação e a conclusão da reinserção da criança, é preciso considerar, primeiramente, o posicionamento da família frente as suas condições materiais e humanas de voltar a assumir o papel de cuidadores dos filhos, tendo em vista a importância do desenvolvimento da criança sob a criação e convívio com os pais, principalmente na primeira infância (Cavalcante, Silva \& Magalhães, 2010; Iannelli, Assis \& Pinto, 2015). Porém, alguns fatores podem dificultar ou facilitar a efetivação desse processo. 
Em uma pesquisa realizada no Sul do Brasil foi investigado os motivos de fracasso na reinserção familiar e o retorno de duas adolescentes para a instituição. Os resultados indicaram que a presença de doença mental nos pais, poucas habilidades parentais, ausência de apoio social, a falta de vínculo com seus filhos, pouca participação nas atividades da comunidade, isolamento social e recusa pelos serviços sociais oferecidos foram situações que ocasionaram uma reinserção familiar malsucedida (Siqueira \& Dell'Aglio, 2011).

Vale ressaltar também que as dificuldades econômicas da família, ausência ou perda do vínculo familiar, agravado pelo elevado tempo de institucionalização, o uso de substâncias psicoativas pelos responsáveis das crianças e adolescentes, a falta de planejamento e acompanhamento das visitas pelas equipes técnicas, ausência de políticas públicas e de ações institucionais de apoio e a baixa adesão das famílias aos encaminhamentos propostos pela instituição, dificultam a reinserção familiar (Brito, Rosa \& Trindade, 2014) de forma saudável, além de aumentar a probabilidade do infante enfrentar o acolhimento, em caso de novo abandono (Siqueira \& Dell'Aglio, 2011).

Diante do exposto, nota-se que a função de quem cuida transcende apenas a preocupação com a higiene e alimentação, para se colocar em matéria de envolvimento pessoal e investimento afetivo. É por meio dessas qualidades que o vínculo é estabelecido e é oferecida à criança os recursos necessários à sua constituição, do momento presente até a hora de ser capaz de caminhar por si só (Maia \& Barreto, 2012).

$$
\text { O entendimento correto da noção }
$$
de vínculo estabelece-se à medida que se entende a condição inicial humana como de absoluto desamparo. A possibilidade de cuidar da sobrevivência de alguém cria condições para que a pessoa ponha em movimento suas esperanças e projetos em torno da criança. Assim, os anos inicias de todas as pessoas baseiam-se no amparo de uma condição indefesa; a vinculação ocorre justamente no laço de alguém que pode oferecer os mais diversos recursos a quem está por construí-los (Saullo, Rosseti-Ferreira \& Amorim 2013).

A necessidade desse componente afetivo é tão ou mais importante que o aspecto mais objetivo do cuidado, como prover sustento e alimentação. A razão disso reside na própria condição humana: o elemento social que nos abriga. Cada indivíduo carrega como potencialidade ir além da sobrevivência, como também dar significado à realidade; o processo de socialização como um todo perpassa pelo interesse, tido aqui como a manifestação 
desse afeto, dos cuidadores em apresentálo intencionalmente as novas pessoas que chegam ao mundo. Pois é a partir desse interesse pessoal que são calcados os valores do grupo e do sistema (Gomes, 2013).

No entanto, a problematização a ser colocada em questão reside em saber quais interesses são esses e como são repassados, de modo a entender como o vínculo é estabelecido entre cuidadores e crianças. Pois mesmo que o processo de socialização envolva regras e normas sociais parecidas, cada ser humano possui particularidades das suas vivências nos primeiros anos de vida - que podem resultar em situações de acolhimento institucional, em que há omissão da sociedade ou família em prover as principais necessidades infantis (Sodré, 2014).

Entender família e sociedade dentro de um todo nomeado sistema, o qual os comportamentos e atitudes da primeira refletem as condições construídas a partir da segunda, impõe a seguinte reflexão: as práticas de cuidado transgeracional feminino estão envolvidas por contextos que determinam dinâmicas familiares, tanto quanto estas dinâmicas auxiliam na manutenção desses contextos (Nunes, Silva \& Pires, 2011). Assim, esta pesquisa teve como objetivo investigar como a dinâmica familiar influenciou o cuidado feminino de crianças em situação de acolhimento institucional.

\section{Método}

O método utilizado foi o estudo de casos múltiplos. A presente pesquisa foi composta por dois estudos de casos. Nos expostos explanados por Yin (2010), que define esta metodologia como "uma pesquisa empírica que investiga um fenômeno contemporâneo em profundidade e em seu contexto de vida real, especialmente quando os limites entre o fenômeno e o contexto não são claramente evidentes". Este método encontra-se consoante com uma abordagem qualitativa de pesquisa, tendo em vista que não se preocupa em confirmar hipóteses pré-existentes, assim como não possui o pressuposto de controle de variáveis.

\section{Participantes}

Para que as participantes pudessem integrar à pesquisa, seguiram-se os seguintes os critérios de inclusão à entrevista: a) os membros deviam pertencer ao sexo feminino, com vistas em mais de uma geração; b) possuírem parentesco consanguíneo com a criança acolhida; c) realizarem visitas regulares à 
instituição; d) serem apontadas como represente legal da criança pela instituição de acolhimento ou como a (s) principal (is) cuidadora (s) da criança. Foram excluídas todas as participantes que não atendessem a esses requisitos, e mais àquelas pessoas diagnosticadas com transtornos psiquiátricos e também familiares femininos que apresentassem alguma forma de risco a integridade física e mental da criança.

\section{Ambiente}

A pesquisa foi realizada numa instituição de acolhimento da região metropolitana de Belém que abrigava crianças de zero a seis anos. O local possuía um espaço destinado ao lazer uma espécie de playground- onde se encontravam brinquedos, uma piscina e uma área ampla de recreação. Havia uma cozinha, a secretaria, uma sala para os membros da limpeza, outra para os motoristas e um quintal onde se lavava as roupas das crianças. Ressalta-se a presença também de uma área destinada às refeições, onde se tinha uma mesa maior, destinada para funcionários e visitantes, e uma mesa menor, para os acolhidos; por fim, existia uma sala para os técnicos da instituição - assistentes sociais, psicólogos e pedagogos - e um local destinado às visitas dos parentes das crianças; este último também era para se realizar entrevistas de cunho acadêmico, como o do presente trabalho.

\section{Instrumentos e Materiais}

A fim de atender ao objetivo da pesquisa, foram utilizados dois instrumentos: a entrevista semiestruturara e o genograma; ambos foram conduzidos em conjunto, de modo a serem complementares. O primeiro deles teve como finalidade coletar dados que permitissem a compreensão do sistema familiar. Já o segundo, construído ao longo da entrevista, foi utilizado para que se expusesse a dinâmica daquele sistema.

\section{Entrevistas Semiestruturadas}

A entrevista semiestruturada investigou itens que incluíam questões relativas aos seguintes pontos: identificação pessoal e de seus familiares (nome, estado civil, idade, ocupação, parentesco); caracterização do sistema familiar (número de uniões, tempo atual da união, número de pessoas que moram na residência e conhecimento sobre as práticas de cuidado); características econômicas e levantamento acerca das relações interpessoais com a família atual e 
com a família externa. Foram entrevistadas duas representes legais, sendo uma a tia da criança e a outra a tia avó. Foram realizadas três entrevistas com cada uma delas, de modo que o genograma pudesse ser montado; a média das entrevistas foi de $45 \mathrm{~min}$.

\section{Genograma}

Segundo McGoldrick (2012), os genogramas registram informações sobre os membros de uma família, colocando em destaque suas relações em pelo menos três gerações; por meio desse instrumento, visualizam-se os membros e os principais eventos que marcaram suas vidas, desde momentos felizes até rupturas emocionais trágicas. O genograma de cada família foi montado na sua frente, com papel e canetas coloridas - para que se pudesse diferenciar determinados pontos da estória familiar.

\section{Materiais}

Foram utilizados papéis folhas de papéis A4 em que foram desenhados os genogramas, canetas esferográficas de cor preta para desenhar os mesmos e canetas coloridas CIS LUMINI para destacar pontos importantes da estória familiar do participante; além destes, utilizou-se um caderno de uso pessoal como diário de campo e um gravador pelo qual se gravou as entrevistas para posterior transcrição.

\section{Cuidados Éticos e Judicias}

Todos os participantes da pesquisa assinaram o Termo de Consentimento Livre e Esclarecido. Os devidos cuidados foram tomados para garantir o sigilo e a confidencialidade das informações, e dessa forma preservar a identidade dos participantes bem como das instituições envolvidas, mesmo com a divulgação dos resultados. Todos nomes apresentados nesse artigo são fictícios.

\section{Análise e Discussão dos Resultados}

Os dados das entrevistas foram sistematizados em categorias temáticas por meio Análise de Conteúdo de Bardin (2010), que a divide em três partes: exploração do material, tratamento dos resultados e interpretação/inferência. Por se tratar de um estudo de casos múltiplos, com o uso de mais de um instrumento, as categorias foram pensadas de modo a incluírem as informações contidas no genograma. A discussão dos resultados foi travada por meio de uma perspectiva teórica sistêmica, de modo que as dinâmicas familiares fossem investigadas 
por meio de uma perspectiva transgeracional.

\section{Resultados e Discussão}

As histórias das famílias foram discutidas com base nos dois casos, tendo no nome da criança institucionalizada sua representação; a primeira foi nomeada Letícia e a outra Evarista. A apresentação de cada narrativa será dividida em partes, com respeito pela linearidade da história; cada um dos excertos será responsável por trazer à tona uma categoria temática a ser discutida.

\section{Perdas Emocionais e Financeiras: o} Contato com a Rua

O caso de Letícia foi contado por sua tia, aqui denominada Caroline; de acordo com o relato da representante legal, sua família apresenta conflitos geracionais, frutos de um sistema historicamente pautado pelo abandono, dificuldade em cuidar de suas crianças e uma gravidez inesperada. Maria e Matheus, avós de Caroline, são os membros mais antigos citados no genograma. Pais de diversas filhas e filhos, aqui são mencionadas apenas duas: Cinthia e Erza. Ambas as filhas conceberam suas crianças cedo, com o desaparecimento de seus companheiros dentro de alguns anos. Viram-se obrigadas a morar com sua nova família na rua, o que desagradou a Maria por ver seus netos sem abrigo; diante disso, a avó viu-se na incumbência de tomar as crianças para si e se responsabilizar pelo cuidado das mesmas, o que reforça a premissa da mulher se colocar a principal cuidadora tendo, inclusive, que assumir responsabilidades que não seriam dela em principal instância. O genograma desta família encontra-se na Figura 1. 


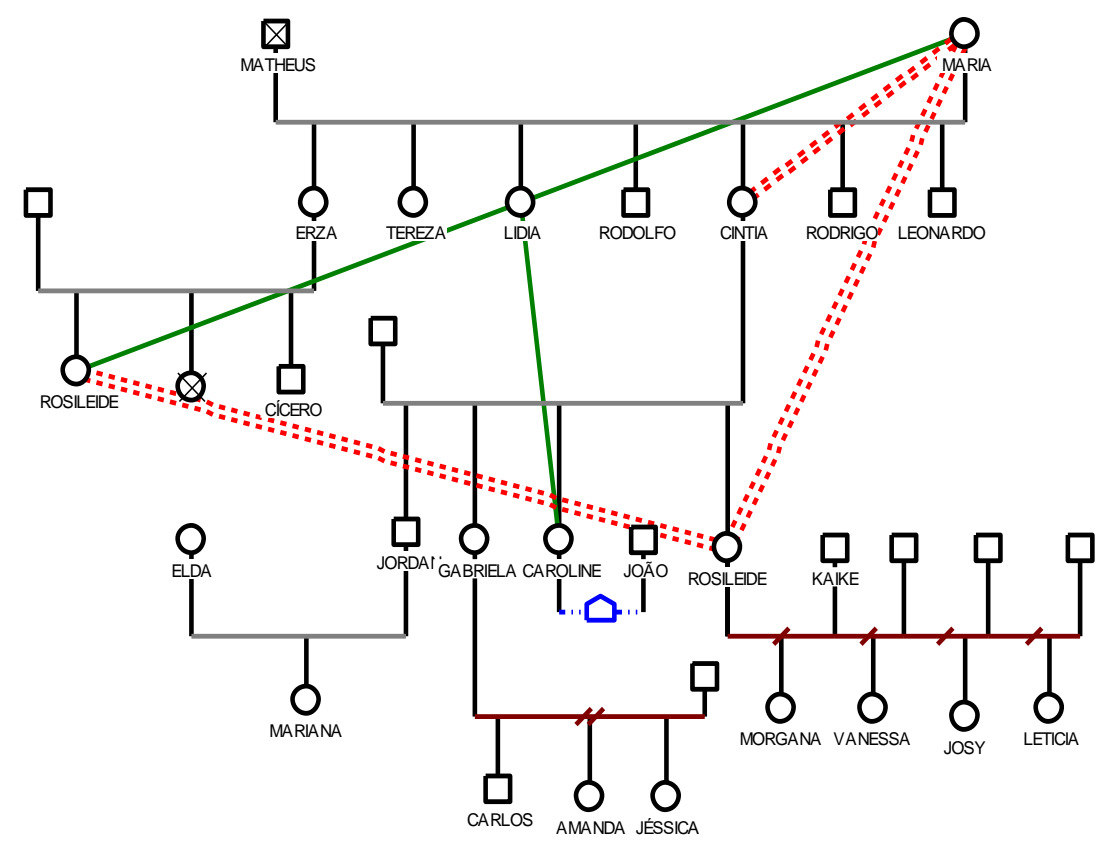

Figura 1: Genograma do caso Letícia

Já o caso de Evarista foi contada por sua tia-avó, Agrepina - sendo esta última filha de Madalena e Jason. Jason falecera cedo, em decorrência de um derrame, o que deixou Madalena sozinha para criar diversos filhos, a quem contou com a ajuda de familiares. Uma das irmãs de Agrepina, Margarida, logo se casou e engravidou. Seu companheiro Marcelo, no entanto, sempre foi conhecido por sua instabilidade no casamento e constantes "fugas". Saía de casa e passava dias a semanas fora. Até que certa vez saiu e nunca mais voltou; isso, além de prejudicar Margarida a nível emocional, também criou dificuldades financeiras a ela, que não obteve qualquer intervenção do Estado para sua situação. Em decorrência do ocorrido, ela e seus filhos passaram a residir na rua.A visualização deste arranjo familiar pode ser vista na Figura 2. 


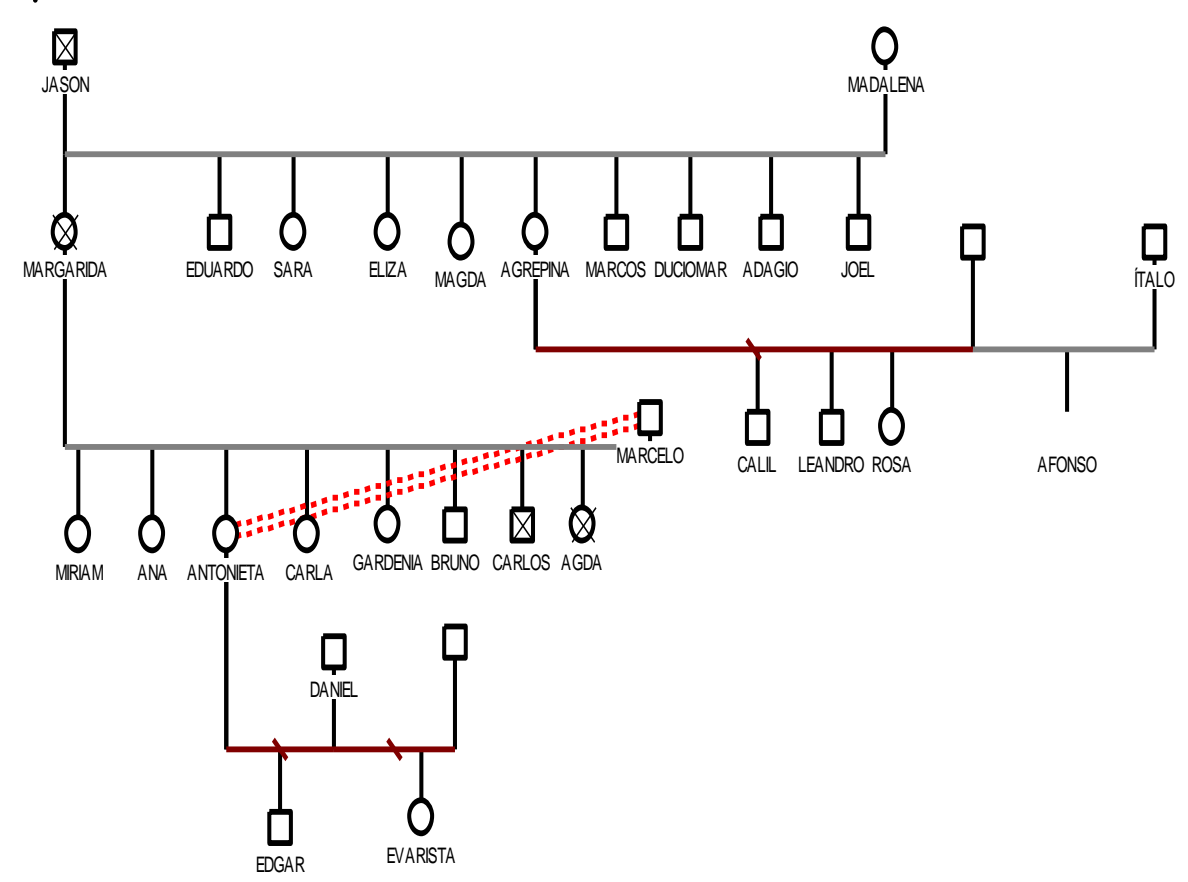

Figura 2: Genograma do caso Evarista

A similaridade destes dois casos começa pela desestruturação da segunda geração apresentada na história, ocasionada pelo abandono do companheiro de seu núcleo familiar; este evento acarretou o mesmo resultado às duas famílias, agora composta pela mãe e suas crianças: o contato e convívio com a rua. Dentro da perspectiva transgeracional, é possível falar de eventos estressores que provocam desagregação familiar e caminham com as próximas gerações, de forma a constituírem a dinâmica relacional daquele grupo a partir de então. Em casos como esses, salienta-se que sem mudanças focadas na compreensão das dinâmicas intergeracionais, quaisquer ganhos futuros, em termos afetivos, podem não ser suficientes para suprirem as consequências da perda (Cúnico \& Arpini, 2013).

Esta discussão coloca em foco, em especial, as crianças de Cinthia, Erza (caso Letícia) e Margarida (caso Evarista), as quais precisaram viver as condições da rua justamente no momento em que se encontravam em processo de desenvolvimento. Ainda transitavam da infância para adolescência, sem nem estarem próximas de chegarem à vida adulta. Parte-se do princípio que esta fase da vida determina de forma considerável características pessoais e relacionais de cada indivíduo. Logo, as chances de que este evento - o de morar na rua - tenha 
influenciado a maneira dos filhos e filhas de Cinthia, Erza e Margarida se relacionarem consigo mesmos e familiares é razoável (Bowen, 1976).

Assim, não se refere apenas à perda do pai como simples desagregação familiar e perda financeira; diz-se da ausência de um membro da família que participava de uma dinâmica singular e específica àquele grupo, a qual já não existe mais. As pessoas que ficaram - no caso a mãe e os filhos - precisaram se organizar para lidar com essa falta. Em termos de transmissão transgeracional, cabia também as crianças lidarem sobre como esta ausência afetou a relação com suas genitoras (Santos \& Ghazzi, 2012). Algo que fica evidente nas seguintes falas das entrevistadas: "foi assim, depois que ele foi embora, parece que o mundo de Cinthia ficou de cabeça para baixo. Nada mais prestou, sabe? As crianças ficaram arredias e não obedeciam a ninguém. Nem a própria mãe. Parecia uma revolta, sabe" - Carolina [sic]. "Foi triste, olha. Foi triste. Marcelo vivia fugindo, a pobre da Margarida ficou na lama. A vizinhança dizia, uma boca só: o olhar das crianças ficou desalentado" Agripina [sic].

Desagregação familiar: conflitos entre a parentela
Cinthia teve quatro filhos e Erzatrês; uma das crianças de Erza nasceu natimorto. Para Cinthia, vieram Rosileide, Jordan, Gabriela e Caroline; Erza teve Rosileide e Cícero. Eventualmente, as irmãs conseguiram retomar de Maria seus filhos, com exceção das duas Rosileides as mais velhas, que já estavam coma avó mais tempo. Caroline relatou que as duas primas, as quais carregavam o mesmo nome, sempre estiveram em conflito; nunca aceitaram morar com sua avó e tinham ressentimento uma da outra. Segundo o relato da entrevistada, isto estava relacionado ao fato de Cinthia e Erza também não se gostarem, assim como nutriam desafeto pela própria mãe.

Quanto a situação de Margarida, a entrevistada mencionou que uma de suas filhas, Antonieta, sentia a falta de seu pai Marcelo, de modo a se apegar à mãe- algo visto como "exagerado", ao que relatou Agrepina. Eventualmente, com ajuda das irmãs e da mãe, a mãe de Antonieta foi capaz de criar seus filhos. Porém, aos 37 anos, Margarida veio a falecer pelo mesmo motivo do pai Jason: derrame cerebral. Todos os seus filhos, antes sem pai, agora viram-se também sem mãe. De acordo com a entrevistada, este foi um evento que desestruturou a família; houvera briga para saber como as crianças de Margarida seriam cuidadas por suas irmãs, pois 
algumas não desejavam ficar com determinados sobrinhos ou se quer se prontificaram a cuidarem de algum.

$\mathrm{O}$ avanço das histórias mostra dois pontos importantes: no caso de Letícia, as filhas de Cinthia e Erza entraram em conflito ao morarem juntas; de algum modo, essa querela refletia também a própria inimizade das irmãs e o ressentimento dessas com sua própria mãe. Em Evarista, a situação foi a oposta: a disputa se dava para saber com quem ficariam as crianças, em que nenhuma das irmãs de Margarida parecia prontificar-se de bom grado. O aparecimento pontual desses conflitos, no entanto, aponta para existência de aspectos da dinâmica familiar considerados como interditos: quando determinadas situações encontram-se expostas, porém são diminuídas nas ações e falas dos familiares (Comin-Scorsolini\& Santos, 2012). As seguintes falas ilustram a assertiva: "Na verdade, era assim: a vovó pegou a gente da mamãe e fingiu como se fosse o normal a se fazer. Como ela é bem rígida, a gente não discute. Nossa mãe e a gente tinha só que aguentar o choro."Caroline [sic] "Ficava assim, sabe. Perguntava pra uma irmã: quer a criança? A resposta: deixa só eu arrumar a casa, daqui a um mês recebo. E nisso os meses se passavam"- Agripina [sic].
O interdito nas famílias apresenta aspectos que não foram inteiramente simbolizados na história daquele grupo e por essa razão são ditos de forma velada, não raras vezes por gestos que aparentam pretensa bondade e boa intenção - mas escondem as dificuldades daquele núcleo. A emergência de situações como essa costumam ser ocasionados por eventos disparadores que funcionam como gatilhos externos para dinâmicas presentes no sistema, as quais ainda não apresentavam uma configuração de fácil identificação (Teodoro, Cardoso \& Freitas, 2010).

Ao levar em conta a situação das duas famílias, discute-se a presença desses conflitos familiares a nível transgeracional e a forma como estes influenciam a situação atual de abandono que algumas membras sofreram, junto às suas crianças. Em suma, o que se pontua é o fato de que um evento presente - a ruptura do vínculo paterno com sua companheira com seus filhos - é somado a problemáticas que já se encontravam instaladas (Almeida, 2010), como bem mostra a fala: "Minha família sempre foi meio assim, resolve tudo sem diálogo. No fundo a gente não se gosta muito, se atura e cumpre o dever de sangue..." - Caroline [sic].

Conhecer uma história familiar e refletir sobre como ela chegou a se constituir do jeito que está requer perceber 
os pontos dessa narrativa que se repetem e são transmitidos pelos seus membros ao longo de sua passagem. É o que se entende por herança transgeracional, a qual pode ser traumática e ocorrer de forma violenta aos membros mais novos (Pereira, Sá \& Miranda, 2013). No caso dessas duas famílias, são evidentes os conflitos que desembocaram nas crianças abandonados por seus pais: entre as duas Rosileides, que representavam disputas maiores entre a avó e a mãe; Antonieta e a falta que seu genitor lhe fazia, sem visualizar um amparo real nas tias.

Separação da Família: o Retorno para Rua

De acordo com Caroline, a Rosileide de Cinthia, aparentava ser a mais revoltada; não apenas pela falta da mãe, mas do pai de quem não tinha quase lembranças. Dizia "não ter família alguma”. Relata a irmã que logo no início da adolescência a jovem se envolveu com drogas, com as quais nunca conseguiu se desvincular. Ao longo dos anos, teve diversos relacionamentos que resultaram em filhos. Retornou para casa da avó algumas vezes, apenas para ser expulsa pela prima com quem morou a vida toda e Erza. Sua última criança, chamada Letícia, foi parar na instituição de acolhimento por estar sendo criada na rua por sua mãe.

No caso Evarista, sem mencionar com qual das tias Antonieta ficou, Agrepina relatou o evento trágico decisivo daquela família; certo dia Antonieta estava responsável por cuidar de sua prima pequena. Tendo ido realizar afazeres domésticos, deixara a criança sozinha com seus brinquedos. Ao chamá-la para comer, não obteve resposta. Encontrou-a afogada dentro de um balde d'água, minutos depois. Consumida pelo pesar e culpa, Antonieta decidira morar na rua, onde teve dois filhos, de companheiros diferentes: Edgar e Evarista. O primeiro ficou sob cuidados do pai, que aceitou ficar com a criança; já Evarista foi entregue pela própria mãe à instituição de acolhimento, a qual relatara não ter condições de ter "nenhuma criança" e que sua filha também não contava com qualquer família, além dela própria.

Aqui se chega ao fim das duas histórias, as quais podem ser visualizadas dentro de fases. De início, existiam apenas as dinâmicas familiares, instituídas, algumas explícitas e conscientes, outras veladas e interditas. $\mathrm{O}$ evento estressor e traumático mexeu nessa dinâmica, tanto quanto revelou as dificuldades que já existiam nela. Por fim, há o estopim desses contextos que resultaram na repetição de 
padrões instalados em mais de uma geração: o contato com a rua nas vidas de Rosileide e Antonieta reverberou em suas filhas, que já na primeira infância não tiveram uma moradia para ficarem. Mesmo tendo a possibilidade de ficarem em alguma residência, os conflitos que envolviam esta escolha se apresentaram como agravantes na vida dessas duas mulheres. Nota-se que certos padrões transgeracionais podem ser construídos ao evitarem ou responderem a antigos padrões. Algo que torna a análise de um sistema ainda mais complexa (Gutfreind, 2010).

Em relação a situação dos dois casos que culminaram com duas mulheres em situação de rua, observa-se que novos elementos passaram a entrar dentro daquela dinâmica familiar e se imiscuíram com os antigos; os padrões não apenas se repetem, como também se atualizam (Rodrigues \& Chalhub, 2014). Num momento anterior, as mães de Antonieta e Rosileide encontraram-se sem uma residência não por desejo, mas sim por fatores contextuais bem específicos. No caso de suas filhas, ambas optarem por saírem de casa. No entanto, se o assim o fizeram, foi por já não se sentirem pertencentes aquele recinto. Algo que fica evidente nas seguintes falas: "Ela [Rosileide] nunca se sentiu em casa, em casa. Sabe? Talvez a rua seja o único lugar que ela possa dizer ser dela..." - Caroline [sic]. "Quando a menina morreu afogada, acho que foi como cair uma ficha pra Antonieta: eu não pertenço aqui. Nunca fiz parte, se fizesse, as coisas não seriam desse jeito..." - Agripina [sic].

A presença de Rosileide e Antonieta nas ruas denuncia rupturas que já vinham sendo desenhadas no seio familiar, desde os eventos que marcaram suas vidas com a ausência de seus pais. Assim como ocorreu nestas situações, novos elementos passam a ser integrados a dinâmica familiar, a exemplo das experiências na rua de ambas as mulheres, diferentes das que suas mães tiveram. Pode-se dizer que o rompimento ocorreu em níveis diferentes, em momentos particulares daquela história, porém dentro da mesma continuidade (Rocha \& Moraes, 2011); foi iniciado a partir dos conflitos de suas mães com outros membros, tendo prosseguido nas saídas de suas filhas de casa e presença das netas Letícia e Evarista nas instituições de acolhimento.

Além das intrigas culminarem em um maior afastamento por parte das duas protagonistas dos seus arranjos familiares mais próximos, houve também a precoce separação das mães em situação de rua e seus filhos. Tanto uma como a outra perderam a guarda de todas as crianças que 
tiveram, o que reforça os resultados encontrados por Crawford, Trotter, Hartshorn e Whitbeck (2011), os quais mostram que cerca de apenas metade das mães desabrigadas possuem contato regular com suas crianças e 1/5 nunca nem se quer as viu.

A perda da guarda das crianças por parte dessas mães, neste caso em específico, não apenas representa uma causalidade da situação em que se encontram, porém, apresenta outro padrão transgeracional: a ausência da mãe. Ambas as mulheres perderam contato com suas genitoras ainda jovens, enquanto que suas filhas mais cedo ainda. Isto coloca em discussão o fato de que os padrões transgeracionais, quando estabelecidos dentro de uma família, tendem a se repetir cada vez mais rápidos, à medida em que suas dinâmicas se aprofundam dentro daquele sistema (Fernandes, Lammy, Morch, Filho \& Coelho, 2011).

\section{Considerações Finais}

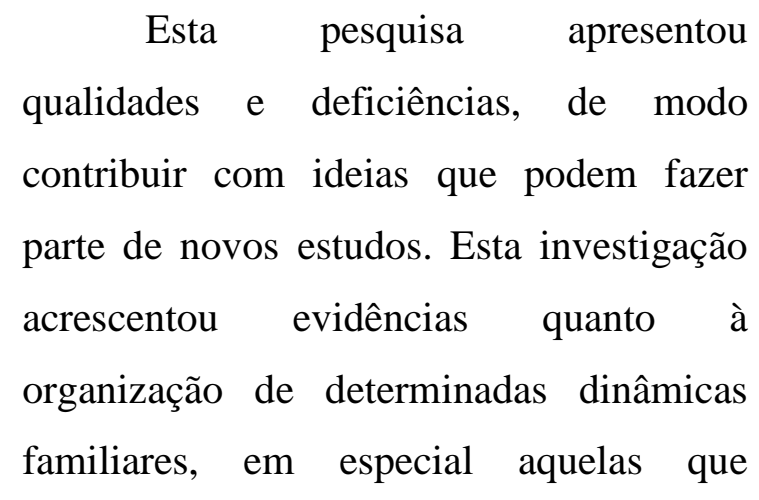

Almeida, M. E. S. (2010). Uma proposta sobre a transgeracionalidade: o absoluto. Agora, 13 (1), 93-108. doi: https://doi.org/10.1590/S151614982010000100007

Almeida, M. E., Magalhães, A. S. \&Féres-Carneiro, Terezinha. (2014). Transmissão geracional na família: repetição e diferenciação. Psico, 45 (4), 454-462. doi: https://doi.org/10.15448/19808623.2014.4.15344

Bardin, Laurence. (2010). Análise de Conteúdo. Lisboa: Edições.

Bowen, M. (1976). Theory in the practice of psychotherapy. New York: Gardner.

Lei $\mathrm{n}^{\circ}$ 8.069, de 13 de julho de 1990. Estatuto da Criança e do Adolescente. Brasília, DF, 1990. 
Recuperado de http://www.planalto.gov.br/ccivil_0 3/leis/18069compilado.htm

Brito, C. O., Rosa, E. M., \& Trindade, Z. A. (2014). O processo de reinserção familiar sob a ótica das equipes técnicas das instituições de acolhimento. Temas em Psicologia, 22 (2), 401-413. doi: http://dx.doi.org/10.9788/TP2014.2 $-11$

Brito, F. S. (2008). Mulher chefe de família: um estudo de gênero sobre a família monoparental feminina. Revista Urutágua, 15, 42-52. Recuperado dehttp://www.urutagua.uem.br/015/ 15brito.htm

Brito, L. M. T. de, Cardoso, A. R., \& Oliveira, J. D. G. (2010). Debates entre Pais e Mães divorciados: um trabalho com grupos. Psicologia: Ciência e Profissão, 30 (4), 810$823 . \quad$ Recuperado dehttp://pepsic.bvsalud.org/scielo.p $\mathrm{hp}$ ? script=sci_arttext\&pid=S141498932010000400011

Bucher-Maluschke, J. S. N. F. (2008). Do transgeracional na perspectiva sistêmica a transmissão psíquica entre as gerações na perspectiva da psicanálise. São Paulo: SummusEditoral.

Cardoso, A. C. (2011). Avós no século XXI: Mutações e rearranjos na família contemporânea. Curitiba: Juruá Editora.

Cavalcante, L. I. C., da Costa Silva, S. S., \& Magalhães, C. M. C. (2010). Institucionalização e reinserção familiar de crianças e adolescentes. Revista

Subjetividade, 10 (4), 1147-1172. Recuperado dehttp://pepsic.bvsalud.org/scielo.p $\mathrm{hp}$ ?script=sci_arttext $\&$ pid=S151861482010000400005

Comin-Scorsolini, Fabio.,\& Antonio dos Santos, Manoel. (2012). A medida positiva dos afetos: bemestar subjetivo (BES) em pessoas casadas. Psicologia: reflexão $e$ crítica, 25 (1), 11-20. doi: https://doi.org/10.1590/S010279722012000100003.

Crawford, D. M., Trotter, E. C., Hartshorn, K. J. S., \&Whitebeck, L. B. (2011). Pregnancy and Mental Health of Young Homeless Women. American Journal of Orthopsyquiatric, 81 (2), 173183. Recuperado dehttps://www.ncbi.nlm.nih.gov/p mc/articles/PMC3383651/

Cúnico, S. D., \&Arpini, D. M. (2013). A família em mudanças: Desafios para a paternidade contemporânea. Pensando

Famílias, 17(1), 28-40. Recuperado dehttp://pepsic.bvsalud.org/scielo.p hp?script=sci_arttext $\&$ pid=S1679494X2013000100004

Diniz, G. R. S. (2011). Conjugalidade e violência: reflexões sob uma ótica de gênero. In Terezinha Fères-Carneiro (Org.), Casal e família: conjugalidade, parentalidade e psicoterapia (1 ed., Cap. 1, pp. 11-26). São Paulo: Casa do Psicólogo.

Fernandes, R. T., Lamy, Z. C., Morsch, Denise., Filho, F. L., \& Coelho, L. F. (2011). Tecendo as teias do abandono: além das percepções das mães de bebês prematuros. Ciência \& Saúde Coletiva, 16 (10), 1-10. doi: https://doi.org/10.1590/S141381232011001100008 
Fukuda, C. C., Penso, M. A., \& Santos, B. R. (2013). Configurações sociofamiliares de crianças com múltiplos acolhimentos institucionais. Arquivos Brasileiros de Psicologia, 65, 70-87. Recuperado dehttp://pepsic.bvsalud.org/scielo.p hp? script=sci_arttext\&pid=S 1809 52672013000100006

Gomes, C. A. V. (2013). O lugar do afetivo no desenvolvimento da criança: implicações educacionais. Psicologia em Estudo, 18 (3), 509518. doi: https://doi.org/10.1590/S141373722013000300012

Gutfreind, Celso. (2010). Narrar, ser mãe, ser pai \& outros ensaios sobre a parentalidade. Rio de Janeiro: DIFEL.

Iannelli, A. M., Assis, S. G., \& Pinto, L. W. (2015). Reintegração familiar de crianças e adolescentes em acolhimento institucional em municípios brasileiros de diferentes portes populacionais. Ciência\& Saúde Coletiva, 20, 39-48. doi: 10.1590/141381232014201.19872013

Knoester, Chris.,\& Carlson, D. L. (2011). Family Structure and the Intergenerational Transmission of Gender Ideology. Journalof Family Issues, 32 (6), 709-734. doi: $10.1177 / 0192513 \times 10396662$

Krom, M. (2000). Família e mitos, prevenção e terapia: resgatando histórias. São Paulo: Summus.

Maia, A. C. \& Barreto, M. (2012). Violência contra crianças e adolescentes no Amazonas: Análise dos registros. Psicologia em Estudo, 17 (2), 195-204.doi:
$10.1590 / \mathrm{S} 1413-$

73722012000200003

McGoldrick, M., \& Carter, B. (1995). As mudanças no ciclo de vida familiar. In B. Carter \& M. McGoldrick (Org.). As Mudanças no Ciclo de Vida Familiar: uma estrutura para terapia familiar (2 ed., Cap. 1, pp. 7-29). Porto Alegre: Artmed.

McGoldrick, Monica. (2012). Genogramas: Avaliação $e$ Intervenção familiar. Rio de Janeiro: Artmed.

Nunes, E. C. D. A., Silva, L. D., \& Pires, E. P. O. R. (2011). O ensino superior de enfermagem: implicações da formação profissional para o cuidado transpessoal. Revista LatinoAmericana de Enfermagem, 19 (2), 01-09.doi:

https://doi.org/10.1590/S010411692011000200005

Pereira, M., Sá, M. D. C., \& Miranda, L. (2013). Adolescência, crise e atenção psicossocial a partir da obra de René Kaës. Saúde em debate, 37 (99), 664-671. doi: https://doi.org/10.1590/S010311042013000400014.

Pines-Gassman, A. (2011). Low-Income Mothers' Nightime and Weekend Work: Daily Associations with Child Behavior, Mother-Child Interactions, and Mood. Family Relations, 60, 15-29.doi: https://doi.org/10.1111/j.17413729.2010.00630.x

Rocha-Coutinho, M. L. (2006). Transmissão geracional e família na contemporaneidade. In Barros. M. L. (Org.). Família e gerações. (1 ed., Cap. 4, pp. 91- 106). Rio de Janeiro: FGV 
Rocha, P. C. X. da.,\& Moras, C. L. (2011). Violência familiar contra a criança e perspectivas de intervenção do Programa Saúde da Família: a experiência do Programa Médico de Família/Niterói. Ciência \& Saúde Coletiva, 16 (7), 32853296.

doi:

https://doi.org/10.1590/S1413-

81232011000800028

Rodrigues, L. S., \&Chalhub, A. A. (2014). Contextos familiares violentos: da vivência de filho à experiência de pai. Pensandofamílias, 18 (2), 77-92. Recuperado dehttp://pepsic.bvsalud.org/scielo.p hp?script=sci_arttext $\&$ pid=S 1679 494X2014000200007

Santos, V. O.\&Ghazzi, M. S. (2012). A transmissão psíquica geracional. Psicologia: ciência e profissão, 32 (3), 632-647. doi: https://doi.org/10.1590/S141498932012000300009.

Saullo, R. F. M., Rossetti-Ferreira, M. C., \& Amorim, K. D. S. (2013). Cuidando ou tomando cuidado? agressividade, mediação e constituição do sujeito- um estudo de caso sobre um bebê mordedor em creche. Pro-Posições, 24(3), 81-98. doi: https://doi.org/10.1590/S010373072013000300006

Silva, T. S. R., Magalhães, C. M. C. \& Cavalcante, L. I. C. (2014). Interações entre avós e netos em instituições de acolhimento infantil. Arquivos Brasileiros de Psicologia, 66, 49-60. Recuperado dehttp://pepsic.bvsalud.org/scielo.p hp?script=sci_arttext\&pid=S180952672014000100005
Siqueira, A. C.\&Dell'Aglio, D. D. (2011). Políticas públicas de garantia do direito à convivência familiar e comunitária. Psicologia \& Sociedade, 23 (2), 262-271. doi: http://dx.doi.org/10.1590/S010271822011000200007

Sodré, F. (2014). O serviço social entre a prevenção e a promoção de saúde: tradução, vínculo e acolhimento. Serviço Social \& Sociedade, 117, 69-83. doi: https://doi.org/10.1590/S010166282014000100005

Teixeira, P. A. S. \&Villachan-Lyra, P. (2015). Sentidos de desacolhimento de mães sociais dos sistemas de casas lares. Psicologia \& Sociedade, 27 (1), 199-210. doi: https://doi.org/10.1590/1807$03102015 \mathrm{v} 27 \mathrm{n} 1 \mathrm{p} 199$.

Teodoro, M. L., Cardoso, B. M.\& Freitas, A. C. H. (2010). Afetividade e conflito familiar e sua relação com a depressão em crianças e adolescentes. Psicologia: Reflexão e Crítica, 23 (2), 324-333. doi: http://dx.doi.org/10.1590/S010279722010000200015

Wendt dos Santos, A. C.\&Moré, C. L. O. O. (2011). Impacto da violência no sistema familiar de mulheres vítimas de agressão. Psicologia: ciência e profissão, 31(2), 220-235. doi: https://doi.org/10.1590/S141498932011000200003

Yin, R. K. (2010). Estudo de Caso: Planejamento e métodos. Bookman editora.

Zanatta, E. A.\& Motta, M. D. G. C. D. (2007). Saberes e práticas de mães no cuidado à criança de zero a seis meses. Revista gaúcha de 
enfermagem, 28 (4), 556-563. Recuperado de https://seer.ufrgs.br/RevistaGaucha deEnfermagem/article/view/3152

Lucas Fadul de Aguiar é psicólogo e mestrando do programa de Pós-Graduação em Psicologia-PPGP/UFPA. É também membro do Laboratório de Desenvolvimento e Saúde (LADS) e Laboratório de Soluções Educacionais (LSE).

E-mail: lucasaguiar531@gmail.com

ORCID: http://orcid.org/0000-0002$\underline{7079-8287}$

Edson Júnior Silva da Cruz é assistente social e professor. Tem Pós-Doutorando em Psicologia no PPGTPC/UFPA. É também membro do Laboratório de Desenvolvimento e Saúde (LADS). E-mail: edsoncruzufpa@gmail.com ORCID: http://orcid.org/0000-0003$\underline{1884-3172}$

Janari da Silva Pedroso é psicólogo e possui doutorado em Ciências. É também professor da Universidade Federal do Pará no Programa de Pós-Graduação em Psicologia e bolsista Produtividade CNPQNível 2.

E-mail: pedrosoufpa@gmail.com ORCID: http://orcid.org/0000-0001$\underline{7602-834 X}$

Enviado em: 23/11/18- Aceito em: 10/07/20 